\title{
THEORETICAL ISSUES OF LANGUAGE CONTACTS, BORROWINGS AND INTERFERENCE
}

\author{
Jerom BAGHANA \\ Belgorod State University, Russia \\ Tatiana G. VOLOSHINA \\ Belgorod State University, Russia \\ Karina I. KOTCH \\ Belgorod State University, Russia \\ Lilia I. RODINA \\ Belgorod State University, Russia \\ Minara A. RADOVICH \\ Belgorod State University, Russia
}

\begin{abstract}
The article is devoted to the theoretical problem of language contacts in modern linguistics. The problem of the relationship between language and consciousness has been comprehensively discussed: various studies of the language picture of the world are carried out by the speakers of a particular language, associative dictionaries of different languages are created, this gives rich material for studying the real perception within a particular culture. To understand how and in which direction the contacting languages change, the authors offer to see the process at three different levels: linguistic level itself, sociolinguistic terms, psycholinguistic terms of individual bilingualism.
\end{abstract}

Keywords: language contact, borrowings, interference, bilinguals, language interaction.

\section{INTRODUCTION}

The study of language contacts in modern linguistics is a separate independent direction. Thus, scientists (Goebl 1997, Weinreich 1953) even talk about "linguistics of language contacts", about "counter-clock linguistics", or "contact linguistics". If we understand these terms directly, we can think that it is not about the direction within the framework of Linguistics, but about independent science, standing in a row, for example, with social linguistics.

There are two groups of factors determining the uniqueness of a particular language: its origin, which determines the place of language in the circle of related languages, its interaction with related and unrelated languages, i.e. language contacts. As noted by N. B. Mech'kovskaya, the origin of language and its contacts are the forces, as if arguing with each other, from opposite sides forming the originality of a particular language (Mech'kovskaya 2000). Genetic heritage acts as an internal structural certainty of language and the basis of its self-development. Language contacts are manifested in their interaction (Baghana \& Chapilina 2017).

\section{METHODS}

This article is based on the systemic approach to the interdisciplinary analysis. Due to the cognitive cross-disciplinary approach, we take into consideration the anthropocentric factor, linguistic and nonlinguistic information, intercultural analyses, especially dealing with the problem of mentality and language correlation. 


\section{RESULTS AND DISCUSSIONS}

The first scientists who specifically pointed to the importance of language contacts as a factor essential for the formation of modern European languages were Italian humanists, who believed, that starting with Lo Renzo Valla, modern Romanesque languages originated from the mixing of Latin with barbaric, primarily German languages. However, these questions have interested linguists of that time in the most General terms and have not been subjected to proper scientific study. In the linguistics of XVII-XVIII centuries these ideas practically did not find further development (Baghana et al. 2014).

The situation changed in the late XVIII-early XIX centuries, when the origin of historically oriented typology, on the one hand, and comparative historical linguistics - on the other, began counting the history of scientific linguistics (Fomichenko 1998).

During the XIX century, comparative-historical linguistics became the main linguistic discipline. The focus of scientists-representatives of this Central line of development of the 19th-century linguistics are the processes of language divergence, and convergent, contact processes are of little interest to them. However, already in the middle of the XIX century linguists pointed to the role of contact influences in the formation of Roman languages. (Paul 1960).

For the first time, the term "language contact" was proposed in linguistics by A. Martine (1952) and introduced into wide use by W. Weinreich, who in his known work "Language contacts", published in 1953, asked basic questions and gave an overview of research in this area. On this topic, later works By E. Haugen (1953) and other foreign linguists were published. The term "language contact" replaced the term "mixing of languages" proposed by G. Shuhardt. The scientist devoted several works to Creole languages, pointing out that there is no language completely devoid of the influence of another language, and that the possibility of mixing knows no boundaries because of each individual studies and changes his language in communication with a number of other individuals (MyersScotton 2002).

The concept of "mixed languages" was unacceptable for specialists in the field of language knowledge, in particular for W. D. Whitney and E. Sapir because of its vagueness. At present, considerable attention is also paid to the issues of language contact. These issues were discussed in the works by V. A. Vinogradov, V. M. Dubova, T. V. Klokov, N. B. Mackowski, A. M. Molodkina, A. Y. Rusakov and foreign linguists as P. Appel, P. Muysken, A. Queffelec, C. Lafage, O. Masumu, C. Myers-Scotton, M. M., Galasso, S. G. Thomason, T. Kaufman, and others.

Changes due to language contacts occur in the history of each language. The development of language outside any influence from the surrounding environment is impossible, so there are no so-called "genetically pure", "unalloyed" languages. Almost any modern language is a fusion of linguistic elements originating from different, related and unrelated languages and dialects (Vinogradov 1997).

A more accurate understanding of the phenomenon of language contacts contributes to its consideration from the point of view of various Sciences - sociology, psychology, linguistics. To understand how and in which direction the contacting languages change, you need to see the process at three different levels:

1) at the linguistic level itself - as a mixture, interpenetration of two independent (self-sufficient) language systems. In general, the aspects of interest to linguists on this issue can be represented as follows:

- what happens to two (or more) in contact with the language at the phonological, grammatical and lexical levels;

- $\quad$ how languages borrow language structures and structural elements from each other;

- what happens to languages that are used simultaneously in bilingual teams;

- what changes are taking place in the contacting languages and how a new language can be developed as a result of their contacts, etc. (Molodkin 2001); 
2) in sociolinguistic terms - as the interaction of multilingual societies, that is, as a certain linguistic situation, which is a set of linguistic formations, that is, languages, serving some society within the boundaries of a certain region, political and territorial association or state. The results of such interaction depend on a number of factors, among which it is possible to note the duration and intensity of contacts between language groups; types of social, economic and political relations between them; functions of languages that serve as a means of communication, etc. However, the outcome of language exposure, depending on the social conditions of exposure can be unpredictable. A. Martinet wrote in this regard:"the Language overcomes its rivals not because of some of its internal qualities, but because its carriers are more militarily, fanatically, culturally concerned" (Martinet 1972). History shows that in similar conditions the fate of languages can be different. The language of a more developed culture does not always take the leading position;

3) in psycholinguistic terms of individual bilingualism. Researchers involved in the psycholinguistic side of language contact, interested in how to get along in the consciousness of bilingual two languages. Depending on the extent to which bilingual speaks two languages, individual bilingualism can be symmetrical (both languages are known to a large extent) or asymmetric (one language is known to a person in a larger volume, the other - in a smaller one). Depending on how to operate the two languages in the speech of bilingual, bilingualism distinguish between Autonomous and combined. When Autonomous brunch/bilingual builds it in each language, using linguistic means of only appropriate language. With the combined bilingualism the speech that a person knows worse, is built on using the means of the first (primary language). However, according to such major linguists as B. Havranek, A. Martin and E. Haugen, complete and Autonomous (without mixing languages) possession of two languages exceeds the mental capabilities of an ordinary man (Martinet 1972).

In addition to the disciplines we mentioned, the issues of language contacts are studied within the framework of anthropology and cultural studies, which, in turn, were the basis for the formation of Sciences related to the General linguistics, namely linguistic anthropology and cultural linguistics.

So, it is possible to conclude that the range of ideas discussed in the theory of language contacts is mainly reduced to the problems of bilingualism, interference and convergence.

Recently, the problem of the relationship between language and consciousness has been comprehensively discussed: various studies of the language picture of the world are carried out by the speakers of a particular language, associative dictionaries of different languages are created, which give a rich material for studying the features of the perception of reality within a particular culture. According to M. V. Zavyalova, each language forms its native speaker a certain image of the world, represented in the language by a semantic network of concepts characteristic for this language: associative experiments and difficulties arising in intercultural communication and translation prove it. Thus, the problem of bilingualism arises how two language systems exist in one person, how two pictures of the world are combined in one consciousness, how two images of reality interact (Zavyalov 2001).

In the linguistic literature, the term interference was introduced by members of the Prague Language School. However, it was widely used only after the publication of the monograph "Language contacts" by W. Weinreich, where the author gave the following definition of interference: "cases of deviations from the norms that occur in the speech of bilingual as a result of the fact that they know more languages than one, i.e. as a result of language contact " (Weinreich 1953).

It follows from the above that the essence of the process of interference is that a person who learns a non-native language, unconsciously changes the system of existing rules, the program of speech behavior, strengthened in the native language, to the studied. Interference is defined as a set of different signs of expressing this meaning in two comparative systems, forming the third, in which the laws of the native and non-native languages operate. Interference is caused by the complexity of the 
introduction and consolidation in the memory of a set of different features of the third system and the unconscious transition to each of the two systems in the construction and understanding of the text.

Due to the fact that the manifestation of linguistic interference is quite varied, it is useful to consider the various types of its implementation. The main types of interference are the following:

- $\quad$ the use of "foreign" language material in the contexts of the language;

- the formation of units from their own language material on the unit of the contacting language;

- the allocation of units of the system functions inherent in their foreign-language correlates;

- $\quad$ stimulating or delaying the impact of units of the system on the functioning of units or models of another;

- $\quad$ leveling the impact of simpler and clearer models of one system on similar but more complex models of the other;

- $\quad$ reproduction of models of the same system by means of another system (Zhluktenko 1974).

In most cases, the causes of interference phenomena can be determined by linguistic methods: by comparing phonetic and grammatical systems of two languages and determining their differences, one usually gets a response of potential forms of interference that are possible in a given contact situation. Often the borrowing of vocabulary can be explained by examining those points in which the dictionary shows its inconsistency with the needs of the cultural environment in which language contact occurs. However, not all potential forms of interference are actually implemented. The exact picture of the impact of bilingualism on an individual's speech varies depending on many factors, some of which can be considered extra-linguistic since they are outside the structural differences of these languages or even outside their linguistic inconsistencies. A complete description of interference in a contact situation, reflecting the spread, persistence and disappearance of individual interference phenomena, is possible only when extralinguistic factors are taken into account.

The depth and volume of interference can be different. They depend on subjective and objective factors. Subjective factors determine the individual language abilities of the speaker, his linguistic competence. The objective factors include the degree of genetic similarity of the contacting languages, individual system-structural properties of the studied language, which determine its specificity. It is noteworthy that the closer the two languages are, the more bilingual the individual relies on the native (primary) language in speech activity in a non-native language. Therefore, related languages, in general, are easier to learn than distant ones, but the interference with this kind of bilingualism is observed more often and is overcome with great difficulty. Thus, the greater the degree of similarity between languages, the greater the probability of interference.

The study of interference is carried out both at the level of comparative structural and linguistic analysis, and at the level of its result-foreign language accent. At the same time, the least studied area of emphasis, and therefore the most vulnerable in practical terms, is considered to be the intonation design of foreign language speech.

Foreign language accent as a manifestation of interference in the speech of a person who speaks two languages can be stable (as a characteristic of the speech of the collective) and transient (as a feature of someone's idiolect).

According to A. A. Reformatsky, the accent is a substitution of unknown sounds and unusual combinations of sounds for their familiar ones and a rethinking of words with their morphological composition and their meanings according to the skills of their language (Reformatski 1999).

The so-called" African accent "especially" betrays " the French-speaking in large units, in lengthy statements. At the same time, errors in the phrasal arrangement and in the choice of the intonation center in the phrase are very obvious. 
In addition to the comparative analysis, which makes it possible to reveal the fields of the probability of interference, the role of the analysis of typical errors is noted, which shows the specific points of this interference and to the extent reveals the nature of its manifestation. These two types of analysis are obligatory, since errors that can be identified by comparison, as it is known, are not always actualized in speech.

The basis of the detection of interference lies in the analysis of the errors, as they are the specific manifestation of it. However, this should not be limited to the study of interference. Error in a foreign language, According to G. M. Burdenyuk and V. M. Grygorevsky, is usually "the result of the wrong operation of the choice of language means of a foreign language for the expression of correctly programmed thought". The reasons for the wrong choice can be different: 1) semantic, structural and functional identification of the phenomena of native and foreign languages, as well as phenomena within a foreign language; 2) the influence of factors such as reinterpretation on the basis of misunderstanding, the emergence of incorrect associations of sometimes purely mechanical character (Burdenyuk \& Grigorevsky 1978).

The fact is that the speaker in his native language is free to express their thoughts helps linguistic flair. Bilingual should switch from the mechanism of native speech to the mechanism of foreign speech. At the same time, due to interference, errors often occur, since in the process of mastering foreign speech we tend to proceed from the peculiarities of speech in our native language.

Interference is a complex unobservable psycholinguistic mechanism that "works" in bilingual's consciousness regardless of his will and desire, manifested in his speech as a deviation from the norm of his native or second language, as the norms of both languages enter into complex relationships, each of which tries to subdue the other.

Studying the data of speech of bilingual individuals, psychologists note that the formation of any language is not an isolated process, independent of the previous experience of the individual (in the study of a new language, the individual necessarily uses his or her past linguistic experience of the native language).

The influence of national specificities of the mentality for the organization of the speech, which is one of the reasons for the occurrence of interference when the contact languages, remains completely undeveloped area. In the scientific literature, there is no clear interpretation of the concept of mentality and a single track of its definition. The mentality is a way of thinking that defines the perception of the world in accordance with the ethnic-social genesis of man and fixed by language that reflects the spiritual qualities of the people speaking the language (Fomichenko 1998).

\section{CONCLUSION}

The analysis of interference phenomena shows it can manifest itself at all language levels-at any site of contacting systems where there are structural differences. The process of inter-ethnic communication is carried out within the framework of often non-matching national mental stereotypes (as is the case in Africa), which is the result of a misunderstanding in the field of communicative behavior of communicating, which is dependent on violations and distortions in the organization of speech behavior of bilingual. The concept of interference implies the reorganization of models, which is the result of the introduction of foreign language elements in those areas of the language that are characterized by a higher structural organization, for example, the Base system of phonemes, most of the morphology and syntax, some of the vocabulary (symbols of kinship, color, weather, etc.).

\section{REFERENCES}

Baghana, J. \& Chapilina, E.V. (2017). “Contact linguistics”. Belgorod: Izdatelstvo BelGU. Baghana, J., Chapilina, E.V. \& Blazhevich, Y.S. (2014). "English borrowings in the territorial English version in Africa". Mocsow: INFRA-M. 
The Turkish Online Journal of Design, Art and Communication - TOJDAC

ISSN: 2146-5193, September 2018 Special Edition, p.1074-1079

Burdenyuk, G.M. \& Grogorievski, V.M. (1978). "Language interference and methods of its foundation". Kishiniov: Shtinitsa.

Fomichenko, L.G. (1998). "Cognitive linguistics as the new way to the research of prosodic interference”. In Linguistic mosaic: Search and discovery: Collection of scientific works, Vol. 1, pp. 215-223. Volgograd: Volgograd Publishing House.

Goebl, H. (1997). "Kontakt linguistik: Ein internationales handbuch zeitgenossischer forschung”, Vol. 2. Berlin.

Martinet, A. (1972). "The language usage and structural linguistics". New Facts in Linguistics, 6, 81-93.

Mech'kovskaya, N.B. (2000). "Social Linguistics”. Moscow: Aspect-Press.

Molodkin, A.M. (2001). "Interaction of languages of different types in ethnic cultures". Saratov: Saratov University Publishing House.

Myers-Scotton, C. (2002). "Contact linguistics: Bilingual encounters and grammatical outcomes". Oxford: Oxford University Press.

Paul, G. (1960). "The Principles of Language History". Moscow: Publishing House of Foreign Literature.

Reformatski, A.A. (1999). "Introduction to linguistics". Moscow: Aspect Press.

Vinogradov, V.A. (1997). "Vvedenie: Imennie kategorii c iazikah Afriki. Osnovi afrikanskogo iazikoznania". Moscow: Aspekt-Press.

Weinreich, W. (1953). "Languages in contact: Finding and problems". New York.

Zavyalov, M. (2001). "Isslodovania rechevikh mekhanizmov pri bilingvizme (na materiale assotsiavnogo eksperimenta c litovsko-russkimi bilingvami)". Issues of Linguistics, 5, 60-85.

Zhluktenko, J.A. (1974). "Linguistic aspects of bilinguals". Kiev: Kiev University. 